\title{
Piyano Çalışma Alışkanlıkları Ölçeği Geliştirme Çalışması
}

DOI: $10.26466 /$ opus.621102

\author{
* \\ Hakan Bağc1 - Alkın Toy ${ }^{* *}$ \\ * Dr. Öğr. Üyesi, Kocaeli Üniversitesi, Güzel Sanatlar Fakültesi, İzmit/ Kocaeli / Türkiye \\ E-Posta: hakan.bagci@kocaeli.edu.tr \\ ORCID: $\underline{0000-0001-5312-3168}$ \\ ** Araştırmacı, İstanbul/ Türkiye \\ E-Posta: alkintoy@gmail.com \\ ORCID: $\underline{0000-0003-3861-4406}$
}

\section{Öz}

Bu çalışmada müzik bölümlerinde okumakta olan öğrencilerin piyano çalışma alışkanlıklarını ölçebilmek amacryla bir ölçek geliştirilmiştir. Ölçek, piyano çalışma sürecinde formal veya informal eğitime dahil öğrencilerin piyano çalışma alışkanlıklarının tespiti bakımından önem taşımaktadır. Geliştirilen ölçek, üniversitelerin müzik ile ilgili farkl programlarında okumakta olan toplam 188 öğrenciye uygulanmıştır. Geliştirilen piyano çalışma alışkanlıkları ölçeği toplam 32 sorudan oluşmakta olup, 5'li likert tipinde bir ölçektir. Puanlamalar 1 ve 5 arasında yapılmıştır. Ölçeğin Cronbach Alfa güvenilirlik katsayısı 0.940 olarak hesaplanmıştır. Yapılan faktör analizi sonucunda piyano çalışma alışkanlıkları ölçeğinin 7 alt boyuttan oluştuğu ve bu sekiz alt boyutun toplam varyansa katkısının \%64.765 olduğu sonucu bulunmuştur. Elde edilen alt boyutlar "Çalgı Tekniği", "Ön Hazırlık ve Isınma", "Postür ve Teknik", "Yorumlama ve Cümleleme", "Ritmik Çalışma ve Parmaklandırma", "Performans Sonrası Etkinlik" ve "Deşifre Tekniği" olarak isimlendirilmiş̧ir. Tüm alt ölçekler birbirleriyle ve toplam puanla 0.001 anlamlılık düzeyinde pozitif ilişki içindedir. Alt ölçeklerin Cronbach Alfa güvenilirlik katsayılarn ise 0.662 ve 0.883 arasında değişmektedir.

Anahtar Kelimeler: Piyano çalışma alışkanlığı, Piyano performansı başarısı, Piyano çalışma yöntemleri, Piyano eğitimi 


\title{
Development of Piano Study Habits Scale
}

\begin{abstract}
In this study, a scale was developed to measure the piano study habits of students studying in music departments. The scale is important in terms of determining the piano study habits of students who are involved in formal or informal education during the piano study process. The scale was applied to a total of 188 students studying in different music programs of universities. The developed piano study habits scale consists of a total of 32 questions and is a 5-point Likert-type scale. Ratings were made between 1 and 5. Cronbach's alpha reliability coefficient of the scale was calculated as 0.940. As a result of the factor analysis, it was found that the piano study habits scale consisted of 7 sub-dimensions and the contribution of these eight sub-dimensions to the total variance was $64.765 \%$. The sub-dimensions obtained were named as "Instrument Technique", "Preparation and Warm-up", "Posture and Technique", "Interpretation and Phrasing", "Rhythmic Work and Fingering", "Post Performance Activity" and "Deciphering Technique" All subscales were positively correlated with each other and with the total score at 0.001 significance level. Cronbach Alpha reliability coefficients of the subscales ranged between 0.662 and 0.883 .
\end{abstract}

Keywords: Piano study habit, Piano performance success, Piano study methods, Piano training 


\section{Giriş}

Alışkanlıklar önceleri ara sıra yapılan, daha sonra rutin haline gelen ve nihayetinde günlük hayatta vazgeçemeyeceğimiz fiillere, düşüncelere ve duygulara dönüşen davranışlardır (Orhan, 2017, s.303). Alışkanlık, düzenli olarak tekrar edilen öğrenilmiş davranış kalıplarıdır. Otomatik olarak gerçekleşen eylemlere yol açar (Gobet, Chassy ve Bilalic, 2011, s.347).

Alışkanlıklar, bireyin öğrenilen otomatik süreçlerinin de ötesine geçer. Selamlar, ritüeller ve diğer sosyal gelenekler toplumlara alışkanlık kazandırır. Birey, bir dili okumayı öğrenirken bazı alışkanlıklar edinir ve gerçek anlamda, dil gelişim zamanı boyunca deyim, yazılı form ve anlama alışkanlıkların kazanır (Graves, 2017, s.283).

Eyleme yol açması nedeniyle alışkanlıklar davranışları tahmin etmemizi sağlar. Alışkanlık aynı zamanda gelecekteki davranışların da bir göstergesidir (Hogg ve Vaughan, 2010, s.105). Bu yüzden başarı için alışkanlıkların önemli bir rolü vardır.

Öğrencilerin piyano çalışma alışkanlıklarını oluşturan birçok tutum ve davranış vardır. Çalgı çalmaya başlamadan gerekli ısınma hareketleri, egzersiz ya da etüt çalışmaları, çalgıya özgü doğru duruş, tutuş ya da konum, eserin incelenmesi (ton/makam, ölçü sayısı, gürlük ve anlatım terimleri, parmak numaraları, dönem özellikleri, pozisyon/konum geçişleri, armonik analizi) deşifre çalışmaları, eser ya da etüdün kısımlara ayrılarak ya da özel çalışmalar yapılarak çalışılması, eser ya da etüdün temposuna göre hızlandırma çalışmaları, ezber çalışması yapmak gibi pek çok temel teknik ve müzikal davranışlar çalışma yöntemleri içerisinde bütün çalgılar için ortak çalışmalardır (Küçükosmanoğlu ve diğ. 2016, s.189).

Piyano eğitiminde öğrenme stratejileri kullanımının öğrencilerin başarı düzeyini arttırmada ve üst bilişsel farkındalık kazanmalarında klasik eğitimden çok daha etkili ve geliştirici olduğu saptanmıştır (Ertem, 2014, s.20).

Günümüzde en yaygın kullanılan öğrenme stratejileri sınıflaması Weinstein ve Mayer (1986) tarafından yapılmıştır (Ertem, 2014, s.20-21): 1- Tekrarlama stratejileri, 2- Anlamlandırma stratejileri, 3- Örgütleme stratejileri, 4Anlamayı izleme stratejileri, 5- Duyuşsal stratejiler.

Piyano çalgısının eğitimi sürecinde üniversite eğitimi süresince her öğrencinin kullanabileceği işlevsel bilgi ve becerilerin kazandırılması gerekmekte- 
dir (Jelen, 2013, s.260). Günümüzde çeşitli çalgılarda performans başarı düzeylerini ölçebilecek araçlara sahip olduğumuz gibi (Abeles, 1973; Barnes, 2002; Ekhohn, 1997) piyano çalgısı için de performans başarısını ölçebilecek ölçü araçları mevcuttur (Grançer, 2009).

Öğrencileri yönlendirmek ve başarı üzerindeki etkisinin sınanması açısından öğretmenler ve araştırmaçların kullanabileceği, piyano çalışma alışkanlıklarını ölçebilecek bir ölçü aracına ihtiyaç duyulmaktadır.

\section{Problem}

Bu çalışmanın temel amacı, üniversitelerin müzikle ilgili bölümlerinde zorunlu dersler arasında yer alan piyano dersi ile ilgili olarak piyano çalışma alışkanlıklarını ölçen geçerli ve güvenilir bir ölçme aracı geliştirmektir.

\section{Yöntem}

Bu bölümde, bir ölçek geliştirme çalışması olan araştırmada; çalışma grubu, ölçme aracı ve elde edilen verilerin analizinde kullanılan tekniklere dair bilgilere aşağıda yer verilmiştir.

\section{Evren ve Örneklem}

Araştırma evrenini üniversitelerin müzik eğitimi ile ilgili farklı bölümlerinde profesyonel öğrenimi gören öğrencilerin tamamı oluşturmuştur. Araştırma örneklemini ise araştırma evreni arasından rasgele seçilen 4 farklı devlet üniversitesinin Güzel Sanatlar Fakültesi müzik bölümlerinde 2017-2018 eğitimöğretim yılında okumakta olan 104 kadın ve 84 erkek olmak üzere toplam 188 öğrenci oluşturmuştur.

Tablo 1. Çalı̧̧ma Grubunda Bulunan Öğrencilerin Bulunduklar Üniversitelere ve Cinsiyetlerine Göre Dağılımı

\begin{tabular}{llll}
\hline Üniversite & Kadın & Erkek & Toplam \\
\hline Kocaeli Üniversitesi GSF & 53 & 36 & 89 \\
Marmara Üniversitesi GSF & 22 & 16 & 38 \\
İnönü Üniversitesi GSF & 15 & 19 & 34 \\
Karabük Üniversitesi GSF & 14 & 13 & 27 \\
Toplam & 104 & 84 & 188 \\
\hline
\end{tabular}


Örneklem grubunda yer alan üniversiteler içinde öğrenci mevcudu açısindan en yoğun öğrenci grubu 89 öğrenci ile Kocaeli Üniversitesi Güzel Sanatlar Fakültesi, en seyrek öğrenci grubu 27 öğrenci ile Karabük Üniversitesi Güzel Sanatlar Fakültesi grubu öğrencileri olarak gözlemlenmiştir.

Tablo 2. Çalışma Grubunda Bulunan Öğrencilerin Bulundukları Üniversitelere ve Cinsiyetlerine Göre Dă̆ılımı

\begin{tabular}{llll}
\hline Üniversite & Kadın & Erkek & Toplam \\
\hline Müzikoloji & 23 & 19 & 42 \\
Performans & 43 & 27 & 70 \\
Müzik & 34 & 25 & 59 \\
Müzik Teknolojisi & 2 & 9 & 11 \\
Türk Halk Müziği & 1 & 3 & 4 \\
Türk Sanat Müziği & 1 & 1 & 2 \\
Toplam & 104 & 84 & 188 \\
\hline
\end{tabular}

Çalışma grubunda yer alan öğrencilerin okumakta oldukları programlar incelendiğinde, Performans programı (70 öğrenci) ve Müzik programlarının (59 öğrenci) en yoğun öğrenci gruplarını oluşturduğu, Türk Sanat Müziği (2 öğrenci) ve Türk Halk Müziği (4 öğrenci) programlarının en az öğrenciye sahip bölümler olduğu görülmüştür.

\section{Ölçeğin Geliştirilmesi}

Ölçeğin geliştirilmesi için öncelikle alan yazın da incelenerek öğrencilerin ya da çalgi çalışan kişilerin sahip olabileceği alışkanlıklar ve yöntemler belirlenmeye çalışılmış ve 52 maddelik bir madde havuzu oluşturulmuştur. Ölçme aracında bulunan maddelerin ölçme aracına uygun olup olmadığı, ölçülmek istenen alanı temsil edip etmediği sorunu ile ilgili olup olmadığı uzman görüşüne göre belirlenir. (Karasar, 1999, s.151). Uzman görüşlerine başvurulması, ölçeğin kapsam geçerliliğini sağlar. Uzman görüşleri de alınarak madde sayısı 32 olarak belirlenmiştir. Söz konusu ölçek, 5'li likert tipinde ölçek olup, puanlamalar 1 ile 5 puan arasında yapılmıştır. 


\section{Verilerin Toplanması}

Oluşturulan ölçek formu, çalışma için seçilen örneklem grubunda yer alan 4 üniversitede öğrenim gören öğrencilere uygulanmış ve öğrenciler özellikle samimi ve içten cevap vermeleri yönünde motive edilmiştir.

\section{Verilerin Analizi}

Çalışma grubunda yer alan öğrencilerden gelen yanıtlar ile ölçeğin geçerlik ve güvenirlik çalışmaları yapılmıştır. Ölçeğin yapısını ortaya koymak amacıyla açıklayıcı faktör analizi yapılmıştır. Piyano Çalışma Alışkanlıkları Ölçeğinin yapı geçerliğini belirlemek için Quartimax döndürme yöntemi ile temel bileşenler analizi kullanılarak Açıklayıcı Faktör Analizi yapılmıştır. Faktör analizi sonucunda ölçek maddelerinin faktör yükünün 0.30 üzerinde olması gerektiği ifade edilmiştir (Büyüköztürk, 2015; Eroğlu, 2008; akt: Evci ve Aylar, 2017, s.50). Analizde faktör yükleri en az 0.30 olarak belirlenmiştir. Ölçeğin alt boyutları ve toplam güvenirlikleri için Cronbach Alpha katsayısı hesaplanmıştır.

\section{Bulgular}

\section{Güvenirliğe İlişkin Bulgular}

Kullanılan ölçekte yer alan 32 soru için Cronbach Alfa iç tutarlılık katsayısı yardımıyla güvenirlik çalışması yapılmıştır. Cronbach Alfa katsayısı 0.940 olarak belirlenmiştir. Bu katsayı oldukça yüksek bir değerdir. Elde edilen Cronbach Alfa değeri, bu ölçeğin Piyano Çalışma Alışkanlıklarını ölçmek için güvenilir bir ölçme aracı olduğunu göstermektedir.

Alışkanlıklarını ölçmek için güvenilir bir ölçme aracı olduğunu göstermektedir.

Bir tutum ölçeğine ilişkin elde edilen Cronbach Alfa Katsayısı değeri, ölçme aracının homojenliğinin bir göstergesi olarak kabul edilmekte olup, hesaplanan Cronbach Alfa Katsayısı 1'e yaklaştığı derecede ölçme aracının tek boyutlu bir yapıya sahip olduğu düşünülebilir (Metin, 2014, s.63). Özdamar, güvenirlik katsayısına ilişkin ölçüt değerlerini aşağıda olduğu gibi ifade etmektedir (Özdamar, 1999; akt: Metin, 2014, s.63): 
- $\quad 0.00<\alpha<0.40$ olduğu zaman ölçek güvenilir değildir

- $0.41<\alpha<0.60$ olduğu zaman ölçek düşük güvenirliktedir

- $\quad 0.61<\alpha<0.80$ olduğu zaman ölçek orta düzeyde güvenilirdir

- $\quad 0.81<\alpha<1.00$ olduğu zaman ölçek yüksek düzeyde güvenilirdir

Tablo 3. Cronbach Alfa Analizi Sonuçlan

\begin{tabular}{ll}
\hline Madde Sayısi & Cronbach Alpha \\
\hline 32 & 0.940 \\
\hline
\end{tabular}

\section{Geçerliliğe İlişkin Bulgular}

Ölçeğin yapı geçerliliğini ortaya koymak ve maddelerin faktör yüklerini belirleyerek boyutlandırabilmek amacıyla faktör analizi yapılmıştır.

Tablo 4. KMO ve Barlett Küresellik Testi

\begin{tabular}{|c|c|c|c|c|c|}
\hline & \multirow{2}{*}{$\begin{array}{l}\text { Madde } \\
\text { Sayısı }\end{array}$} & \multirow{2}{*}{ KMO } & \multicolumn{3}{|c|}{ Bartlett Küresellik Testi } \\
\hline & & & Ki Kare & sd & $p$ \\
\hline $\begin{array}{l}\text { Piyano Çalışma } \\
\text { Alışkanlıkları Ölçeği }\end{array}$ & 32 & 0.891 & 3331.133 & 496 & $<0.001$ \\
\hline
\end{tabular}

Faktör analizinde örneklem büyüklüğünün yeterliliğini test etmek için ise Kaiser-Meyer-Olkin (KMO) testi yapılmalıdır. KMO ölçütü 0.90-1.00 arasinda ise "mükemmel", 0.80-0.89 arasında ise "çok iyi", 0.70-0.79 arasında ise "iyi", 0.60-0.69 arasında ise "orta", 0.50-0.59 arasında ise "zayıf" ve 0.50'nin altında ise "kabul edilemez"dir. Çalışmadan elde edilen KMO değeri 0.891olup, örneklemin yeterliliğinin çok iyi olduğu söylenilebilir (Akgül, 2005; akt: Sarı, 2016: 28).

Verilerin Faktör analizine uygun olup olmadığını belirlemek için Bartelett Küresellik Testi yapılmıştır. Bartlett testinde, korelasyon matrisi birim matristir şeklinde ifade edilen sıfır hipotezinin reddedilmesi gerekir. Bartlett Küresellik testi ile, sonucuna göre, hesaplanan kare istatistiği değeri 3331.133'tür $(\mathrm{p}<0.001)$. Buradan sıfir hipotezi reddedilmiştir ve verilerin faktör analizine uygun olduğu ifade edilebilir. 


\section{Faktör Analizi Sonuçları}

Tablo 5. Ölçekte Yer Alan Maddelerin Tanımlayıcı Değerleri

\begin{tabular}{llll}
\hline Madde & $\mathbf{N}$ & Aritmetik Ortalama & StandartSapma \\
\hline Madde 1 & 188 & 3.7766 & 1.31754 \\
Madde 2 & 188 & 3.8830 & 1.18237 \\
Madde 3 & 188 & 4.0638 & 1.04250 \\
Madde 4 & 188 & 4.0638 & 0.96803 \\
Madde 5 & 188 & 4.2181 & 0.93093 \\
Madde 6 & 188 & 3.8989 & 1.11643 \\
Madde 7 & 188 & 2.6117 & 1.17609 \\
Madde 8 & 188 & 3.6223 & 1.16588 \\
Madde 9 & 188 & 3.8723 & 1.13037 \\
Madde 10 & 188 & 3.6011 & 1.13071 \\
Madde 11 & 188 & 3.7234 & 1.06379 \\
Madde 12 & 188 & 3.1489 & 1.24064 \\
Madde 13 & 188 & 3.0745 & 1.34235 \\
Madde 14 & 188 & 3.4681 & 1.30979 \\
Madde 15 & 188 & 3.6702 & 1.20061 \\
Madde 16 & 188 & 3.5479 & 1.26780 \\
Madde 17 & 188 & 4.0479 & 1.11040 \\
Madde 18 & 188 & 3.5000 & 1.23885 \\
Madde 19 & 188 & 3.6330 & 1.15086 \\
Madde 20 & 188 & 4.1755 & 0.99520 \\
Madde 21 & 188 & 3.7872 & 1.14109 \\
Madde 22 & 188 & 4.0691 & 1.03444 \\
Madde 23 & 188 & 3.5532 & 1.15270 \\
Madde 24 & 188 & 3.8989 & 1.04211 \\
Madde 25 & 188 & 3.6596 & 1.07029 \\
Madde 26 & 188 & 3.3457 & 1.21604 \\
Madde 27 & 188 & 3.8191 & 0.99692 \\
Madde 28 & 188 & 3.6011 & 1.21726 \\
Madde 29 & 188 & 4.1117 & 1.09908 \\
Madde 30 & 188 & 3.7181 & 1.34005 \\
Madde 31 & 188 & 3.0798 & 1.21968 \\
Madde 32 & 188 & 3.3777 & \\
Madde 32 & 188 & 3.3777 & \\
\hline
\end{tabular}

Ölçekte yer alan sorulara ilişkin aritmetik ortalama ve standart sapma değerleri yukarıdaki tabloda yer almaktadır. Aritmetik ortalaması en yüksek olan soru 29. Soru olup A.O. değeri 4.1117 olarak belirlenmiştir. Aritmetik ortalaması en düşük olan soru 7. Soru olup A.O. değeri 2.6117 olarak belirlenmiştir. 
Tablo 6. Temel Bileşenler Analizi - Faktör Yükleri (Communalities)

\begin{tabular}{|c|c|c|}
\hline Madde & Başlangıç & Yük \\
\hline Madde 1 & 1.000 & 0.702 \\
\hline Madde 2 & 1.000 & 0.750 \\
\hline Madde 3 & 1.000 & 0.759 \\
\hline Madde 4 & 1.000 & 0.721 \\
\hline Madde 5 & 1.000 & 0.709 \\
\hline Madde 6 & 1.000 & 0.631 \\
\hline Madde 7 & 1.000 & 0.589 \\
\hline Madde 8 & 1.000 & 0.729 \\
\hline Madde 9 & 1.000 & 0.657 \\
\hline Madde 10 & 1.000 & 0.651 \\
\hline Madde 11 & 1.000 & 0.573 \\
\hline Madde 12 & 1.000 & 0.459 \\
\hline Madde 13 & 1.000 & 0.620 \\
\hline Madde 14 & 1.000 & 0.693 \\
\hline Madde 15 & 1.000 & 0.639 \\
\hline Madde 16 & 1.000 & 0.834 \\
\hline Madde 17 & 1.000 & 0.630 \\
\hline Madde 18 & 1.000 & 0.682 \\
\hline Madde 19 & 1.000 & 0.611 \\
\hline Madde 20 & 1.000 & 0.684 \\
\hline Madde 21 & 1.000 & 0.735 \\
\hline Madde 22 & 1.000 & 0.628 \\
\hline Madde 23 & 1.000 & 0.615 \\
\hline Madde 24 & 1.000 & 0.535 \\
\hline Madde 25 & 1.000 & 0.770 \\
\hline Madde 26 & 1.000 & 0.604 \\
\hline Madde 27 & 1.000 & 0.556 \\
\hline Madde 28 & 1.000 & 0.597 \\
\hline Madde 29 & 1.000 & 0.669 \\
\hline Madde 30 & 1.000 & 0.608 \\
\hline Madde 31 & 1.000 & 0.655 \\
\hline Madde 32 & 1.000 & 0.648 \\
\hline
\end{tabular}

Yukarıdaki tablo, her bir faktörün toplam faktörü ne kadarını etkilediğini göstermektedir. Bu tabloda 0.30'un altındakiler çıkarılarak işlem tekrar edilir (Büyüköztürk, 2015; Eroğlu, 2008). Faktör yükü 0.30 değerinin altında olan herhangi bir madde görülmemiş olup, en küçük faktör yükü 0.459 olarak 12 . maddede görülmüştür. Ölçeğin uygulanan ilk uygulanan formundan herhangi bir maddenin çıkarılmasına ihtiyaç duyulmamıştır. 
Tablo 7. Açıklayıcı Faktör Analizi - Varyans Açıklama Tablosu

\begin{tabular}{|c|c|c|c|c|c|c|}
\hline \multirow{2}{*}{ Madde } & \multicolumn{3}{|c|}{ Başlangıç Özdeğerleri } & \multicolumn{3}{|c|}{$\begin{array}{l}\text { Elde Edilen Faktörlerin Varyans ve } \\
\text { Özdeğerleri }\end{array}$} \\
\hline & Özdeğer & $\begin{array}{l}\text { Varyans } \\
\text { Yüzdesi }\end{array}$ & $\begin{array}{l}\text { Kümülatif } \\
\text { Yüzde }\end{array}$ & Özdeğer & $\begin{array}{l}\text { Varyans } \\
\text { Yüzdesi }\end{array}$ & $\begin{array}{l}\text { Kümülatif } \\
\text { Yüzde }\end{array}$ \\
\hline 1 & 11.409 & 35.653 & 35.653 & 11.409 & 35.653 & 35.653 \\
\hline 2 & 2.100 & 6.563 & 42.216 & 2.100 & 6.563 & 42.216 \\
\hline 3 & 1.983 & 6.196 & 48.411 & 1.983 & 6.196 & 48.411 \\
\hline 4 & 1.697 & 5.304 & 53.715 & 1.697 & 5.304 & 53.715 \\
\hline 5 & 1.563 & 4.884 & 58.599 & 1.563 & 4.884 & 58.599 \\
\hline 6 & 1.160 & 3.625 & 62.224 & 1.160 & 3.625 & 62.224 \\
\hline 7 & 1.032 & 3.224 & 65.448 & 1.032 & 3.224 & 65.448 \\
\hline 8 & 0.925 & 2.889 & 68.337 & & & \\
\hline 9 & 0.850 & 2.656 & 70.994 & & & \\
\hline 10 & 0.799 & 2.498 & 73.491 & & & \\
\hline 11 & 0.754 & 2.355 & 75.846 & & & \\
\hline 12 & 0.640 & 2.001 & 77.847 & & & \\
\hline 13 & 0.616 & 1.926 & 79.773 & & & \\
\hline 14 & 0.601 & 1.879 & 81.652 & & & \\
\hline 15 & 0.577 & 1.804 & 83.456 & & & \\
\hline 16 & 0.540 & 1.687 & 85.142 & & & \\
\hline 17 & 0.484 & 1.512 & 86.654 & & & \\
\hline 18 & 0.457 & 1.428 & 88.082 & & & \\
\hline 19 & 0.446 & 1.394 & 89.476 & & & \\
\hline 20 & 0.418 & 1.307 & 90.783 & & & \\
\hline 21 & 0.393 & 1.227 & 92.010 & & & \\
\hline 22 & 0.351 & 1.096 & 93.106 & & & \\
\hline 23 & 0.316 & 0.987 & 94.093 & & & \\
\hline 24 & 0.291 & 0.909 & 95.001 & & & \\
\hline 25 & 0.266 & 0.832 & 95.834 & & & \\
\hline 26 & 0.252 & 0.788 & 96.621 & & & \\
\hline 27 & 0.230 & 0.718 & 97.340 & & & \\
\hline 28 & 0.215 & 0.673 & 98.013 & & & \\
\hline 29 & 0.177 & 0.552 & 98.565 & & & \\
\hline 30 & 0.174 & 0.543 & 99.108 & & & \\
\hline 31 & 0.148 & 0.462 & 99.570 & & & \\
\hline 32 & 0.138 & 0.430 & 100.000 & & & \\
\hline
\end{tabular}

Yapılan faktör analizi sonucunda, özdeğeri 1'den büyük olan 7 faktör ortaya çıkmıştır Özdeğerleri sırasıyla, 11.409, 2.100, 1.983, 1.697, 1.563, 1.160 ve 1.032 olarak hesaplanmıştır. Bu 7 faktörün varyans açıklama oranı $\% 65.448$ 'tür. 
Tablo 8. Quartimax Döndürülmüş Temel Bileşenler Analizi

\begin{tabular}{|c|c|c|c|c|c|c|c|}
\hline \multirow{2}{*}{ Madde } & \multicolumn{7}{|c|}{ Alt Ölçek } \\
\hline & 1 & 2 & 3 & 4 & 5 & 6 & 7 \\
\hline 16 & 0.856 & & & & & & \\
\hline 14 & 0.716 & & & & & & \\
\hline 13 & 0.695 & & & & & & \\
\hline 21 & 0.626 & & & & & & \\
\hline 18 & 0.624 & & & & & & \\
\hline 15 & 0.579 & & & & & & \\
\hline 19 & 0.514 & & & & & & \\
\hline 2 & & 0.806 & & & & & \\
\hline 1 & & 0.772 & & & & & \\
\hline 3 & & 0.737 & & & & & \\
\hline 10 & & 0.687 & & & & & \\
\hline 11 & & 0.552 & & & & & \\
\hline 12 & & 0.524 & & & & & \\
\hline 7 & & 0.439 & & & & & \\
\hline 25 & & & 0.789 & & & & \\
\hline 8 & & & 0.783 & & & & \\
\hline 9 & & & 0.695 & & & & \\
\hline 27 & & & 0.508 & & & & \\
\hline 17 & & & 0.463 & & & & \\
\hline 4 & & & & 0.757 & & & \\
\hline 5 & & & & 0.673 & & & \\
\hline 6 & & & & 0.589 & & & \\
\hline 30 & & & & 0.398 & & & \\
\hline 29 & & & & & 0.699 & & \\
\hline 20 & & & & & 0.635 & & \\
\hline 28 & & & & & 0.561 & & \\
\hline 32 & & & & & & 0.733 & \\
\hline 31 & & & & & & 0.706 & \\
\hline 26 & & & & & & 0.550 & \\
\hline 23 & & & & & & & 0.718 \\
\hline 22 & & & & & & & 0.558 \\
\hline 24 & & & & & & & 0.426 \\
\hline
\end{tabular}

Kaiser Normalizasyon ile Quartimax yöntemi ile döndürülerek elde edilen temel bileşenler analizinde, 1 . alt ölçekte 7 madde $(16,14,13$, 21, 18, 15 ve 19. maddeler), 2 . alt ölçekte 7 madde $(2,1,3,10,11,12$ ve 7 . maddeler), 3 . alt ölçekte 5 madde $(25,8,9,27$ ve 17. maddeler), 4 . alt ölçekte 4 madde $(4,5,6$ ve 30. maddeler), 5. alt ölçekte 3 madde (29, 20 ve 28. maddeler), 6 . alt ölçekte 3 madde (32, 31 ve 26 . madde), 7 . alt ölçekte 3 madde $(5,24,23$. maddeler) ve 8 . Alt ölçekte 1 madde (23, 22 ve 24 . madde) yer almıştır. 
Tablo 9. Piyano Çalışma Alışkanlıkları Ölçeği Alt Ölçek Güvenilirliklerine İlişkin Veriler

\begin{tabular}{|c|c|c|c|c|c|}
\hline $\begin{array}{l}\text { Piyano Çalışma Alışkanlıkları } \\
\text { Değerlendirme Faktörleri }\end{array}$ & $\begin{array}{l}\text { Öz } \\
\text { Değer- } \\
\text { ler }\end{array}$ & $\begin{array}{l}\text { Faktör } \\
\text { Yükleri }\end{array}$ & $\begin{array}{l}\text { Açıklanan } \\
\text { Varyans } \\
\text { Yüzdesi }\end{array}$ & $\begin{array}{l}\text { Toplam } \\
\text { V.A.Y }\end{array}$ & $\begin{array}{l}\text { Alt } \\
\text { Ölçek } \\
\text { Güveni- } \\
\text { lirlik }\end{array}$ \\
\hline Faktör 1: Çalgı Tekniği & 11.409 & & 35.653 & 35.653 & 0.883 \\
\hline $\begin{array}{l}\text { 16. Çalıştı̆̆ım eserlerin dönemsel özellik- } \\
\text { lerini içeren farklı yorumlarını dinlerim. }\end{array}$ & & 0.856 & & & \\
\hline $\begin{array}{l}\text { 14. Çalıştı̆̆ım eserlerdeki dönemin stil } \\
\text { özelliklerine (pedal, parmak, bilek) göre } \\
\text { çalmaya dikkat ederim. }\end{array}$ & & 0.716 & & & \\
\hline $\begin{array}{l}\text { 13. Çalış̧ı̆̆ım eserlerin dönemsel özellik- } \\
\text { lerini araştırırım. }\end{array}$ & & 0.695 & & & \\
\hline $\begin{array}{l}\text { 21. Bir eseri çalışmadan önce farklı sanat- } \\
\text { çlardan yorumlanış biçimlerini dinlerim. }\end{array}$ & & 0.626 & & & \\
\hline $\begin{array}{l}\text { 18. Eserleri çalşırken dönemsel ve stil } \\
\text { özelliklerine göre pedal kullanımını dik- } \\
\text { kat ederim. }\end{array}$ & & 0.624 & & & \\
\hline $\begin{array}{l}\text { 15. Çalıştı̆̆ım eserlerin hangi teknikleri } \\
\text { içerdiğine dikkat ederim. }\end{array}$ & & 0.579 & & & \\
\hline $\begin{array}{l}\text { 19. İki elde farklı çalım tekniklerine sahip } \\
\text { pasajları çalışırken, nelere dikkat etmem } \\
\text { gerektiğini araştırırım. }\end{array}$ & & 0.514 & & & \\
\hline Faktör 2: Ön Hazırlık ve Isınma & 2.100 & & 6.563 & 42.216 & 0.868 \\
\hline 2. Parmak egzersizleri yaparım. & & 0.806 & & & \\
\hline $\begin{array}{l}\text { 1. Çalışmaya başlamadan önce ısınma eg- } \\
\text { zersizleri (parmak, el, bilek) yaparım. }\end{array}$ & & 0.772 & & & \\
\hline 3. Gam çalışmaları yaparım. & & 0.737 & & & \\
\hline 10. Temel ısınma etütlerini yaparım. & & 0.687 & & & \\
\hline $\begin{array}{l}\text { 11. Temel gam dizilişlerini melodik ve ar- } \\
\text { monik olarak çalışırı. }\end{array}$ & & 0.552 & & & \\
\hline $\begin{array}{l}\text { 12. Temel gam dizilişlerini kromatik ola- } \\
\text { rak çalışrım. }\end{array}$ & & 0.524 & & & \\
\hline $\begin{array}{l}\text { 7. Piyano çalışmaya başlamadan önce vü- } \\
\text { cut esnekliğini sağlayacak kültür - fizik } \\
\text { hareketlerini yaparım. }\end{array}$ & & 0.439 & & & \\
\hline Faktör 3: Postür ve Teknik & 1.983 & & 6.196 & 48.411 & 0.839 \\
\hline $\begin{array}{l}\text { 25. Piyano çalışırken temel oturuş pozis- } \\
\text { yonunu bozmadan çalışmaya özen göste- } \\
\text { ririm. }\end{array}$ & & 0.789 & & & \\
\hline $\begin{array}{l}\text { 8. Piyano çalmaya başlamadan önce temel } \\
\text { oturuş pozisyonumu kontrol ederim. }\end{array}$ & & 0.783 & & & \\
\hline $\begin{array}{l}\text { 9. Piyano çalarken el ve bilek pozisyonu- } \\
\text { nun nasıl olması gerektiğini düşünürüm. }\end{array}$ & & 0.695 & & & \\
\hline $\begin{array}{l}\text { 27. Piyano çalışrken el, bilek ve kollarımı } \\
\text { en uygun pozisyonda tutarım. }\end{array}$ & & 0.508 & & & \\
\hline
\end{tabular}




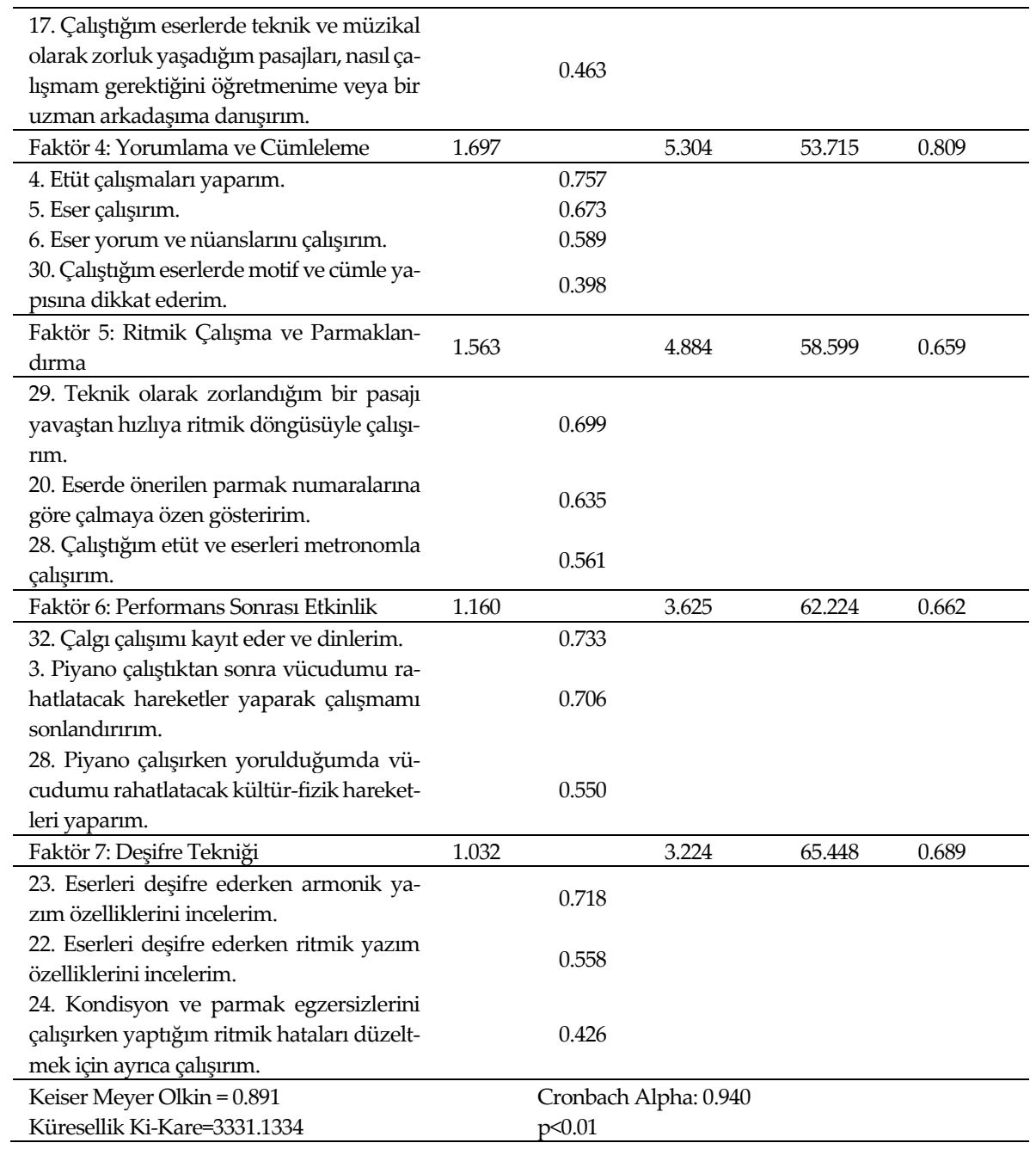

- Birinci faktörün varyans açıklama oranı \%35.653'tür. Birinci faktörde 7 madde yer almıştır. Bu faktör "Çalgı Tekniği" olarak adlandırılabilir.

- İkinci faktörde 7 madde yer almıştır ve varyans açıklama oranı \%6.563'tür. Bu faktöre de "Ön Hazırlık ve Isınma" adı verilebilir.

- U U̇çüncü faktörün varyans açılama oran \%6.196olup, 5 madde bu faktörde toplanmıştır. Bu faktör ise, "Postür ve Teknik" olarak adlandırılabilir. 
- Dördüncü faktörün varyans açiklama oranı \%5.304'tür. Bu faktör 4 maddenin toplandığı ve "Yorumlama ve Cümleleme" olarak adlandırılabilen bir faktördür.

- Beşinci faktörün varyans açıklama oranı \%4.884 ve bu faktörde 3 madde yer almaktadır. Bu faktör de "Ritmik Çalışma ve Parmaklandırma" olarak isimlendirilebilir.

- Altıncı faktörde 3 madde yer almakta olup, varyans açklama oranı \%3.625'tir. Bu faktör, "Performans Sonrası Etkinlik" olarak adlandırılmiştır.

- Yedinci faktörün varyans açıklama oranı \%3.224'tür. Bu faktörde, 3 madde yer almıştır. Bu faktör de “Deşifre Tekniği”" olarak adlandırılmıştir.

Ayrıca, Tablo 9'da her faktörde yer alan maddelerin faktör yükleri ile her bir faktöre ilişkin Cronbach Alpha güvenirlik katsayıları yer almaktadır. Faktör yüklerinin 0.398 ile 0.856 arasında değiştiği görülmektedir. Her bir faktörün Cronbach Alpha güvenirlik katsayıları incelendiğinde, katsayıların 0.662 ile 0.883 arasında değiştiği görülmektedir. Bu durum, her bir faktörün güvenilir olduğunu göstermektedir.

Herbir faktörün, faktör yükleri ayrı ayrı incelendiğinde, 1. Faktörün, faktör yükleri 0.514 ile 0.856 arasında; 2 . Faktörün, faktör yükleri 0.439 ile 0.806 arasında; 3. Faktörün, faktör yükleri 0.463 ile 0.789 arasında; 4. Faktörün, faktör yükleri 0.398 ile 0.757 arasında; 5 . Faktörün, faktör yükleri 0.561 ile 0.699 arasında; 6. Faktörün, faktör yükleri 0.550 ile 0.733 arasında ve 7 . Faktörün, faktör yüklerinin de 0.426 ile 0.718 arasında olduğu belirlenmiştir. 
Tablo 10. Piyano Çalışma Alışkanlıkları Ölçeği Alt Faktörleri ve Toplam Puanları Arasında Yapılan Pearson Çarpım Momentler Katsayısı Korelasyonları

\begin{tabular}{llll}
\hline Ölçek & $n$ & $r$ & $p$ \\
\hline Faktör 1 - Toplam & 188 & 0.839 & 0.000 \\
Faktör 2 - Toplam & 188 & 0.808 & 0.000 \\
Faktör 3 - Toplam & 188 & 0.800 & 0.000 \\
Faktör 4 - Toplam & 188 & 0.768 & 0.000 \\
Faktör 5 - Toplam & 188 & 0.657 & 0.000 \\
Faktör 6 - Toplam & 188 & 0.618 & 0.000 \\
Faktör 7 - Toplam & 188 & 0.696 & 0.000 \\
Faktör 1 - Faktör 2 & 188 & 0.581 & 0.000 \\
Faktör 1 - Faktör 3 & 188 & 0.635 & 0.000 \\
Faktör 1 - Faktör 4 & 188 & 0.619 & 0.000 \\
Faktör 1 - Faktör 5 & 188 & 0.417 & 0.000 \\
Faktör 1 - Faktör 6 & 188 & 0.373 & 0.000 \\
Faktör 1 - Faktör 7 & 188 & 0.455 & 0.000 \\
Faktör 2 - Faktör 3 & 188 & 0.555 & 0.000 \\
Faktör 2 - Faktör 4 & 188 & 0.591 & 0.000 \\
Faktör 2 - Faktör 5 & 188 & 0.494 & 0.000 \\
Faktör 2 - Faktör 6 & 188 & 0.438 & 0.000 \\
Faktör 2 - Faktör 7 & 188 & 0.490 & 0.000 \\
Faktör 3 - Faktör 4 & 188 & 0.490 & 0.000 \\
Faktör 3 - Faktör 5 & 188 & 0.479 & 0.000 \\
Faktör 3 - Faktör 6 & 188 & 0.460 & 0.000 \\
Faktör 3 - Faktör 7 & 188 & 0.482 & 0.000 \\
Faktör 4 - Faktör 5 & 188 & 0.446 & 0.000 \\
Faktör 4 - Faktör 6 & 188 & 0.359 & 0.000 \\
Faktör 4 - Faktör 7 & 188 & 0.527 & 0.000 \\
Faktör 5 - Faktör 6 & 188 & 0.350 & 0.000 \\
Faktör 5 - Faktör 7 & 188 & 0.509 & 0.000 \\
Faktör 6 - Faktör 7 & 188 & 0.460 &
\end{tabular}

Piyano Çalışma Alışkanlıkları Ölçeğinin alt ölçeklerinin tamamının kendi aralarında ve toplam puanla arasında 0.001 anlamlılık düzeyinde güçlü ilişkiler sergilediği görülmüştür. Aralarında ortaya çıkan en güçlü ilişkiler ölçek toplam puanı ve 1. alt ölçek puanları arasında ( $\mathrm{r}=0.839)$, ölçek toplam puanı ve 2. alt ölçek puanları arasında ( $\mathrm{r}=0.808)$, ölçek toplam puanı ve 3. alt ölçek puanları arasındadır $(\mathrm{r}=0.800)$. Görülen en en zayıf ilişkiler ise sırasıyla 5 . ve 6. alt ölçekler arasında $(\mathrm{r}=0.350)$, 4 . ve 6 . alt ölçekler arasında $(\mathrm{r}=0.359)$ ve 1 . ve 6. alt ölçekler arasındadır ( $\mathrm{r}=0.373)$. 


\section{Sonuç}

Bu çalışmada Piyano Çalışma Alışkanlıklarını ölçmek amacıyla toplamda 32 maddeden oluşan bir ölçü aracı geliştirilmiştir. Ölçeğin Cronbach Alfa katsayısı 0.940 olarak hesaplanmıştır. Ölçek, 5'li likert tipi bir ölçek olup, puanlamalar 1 ile 5 puan arası yapılmıştır.

7 alt boyuttan oluşan ölçek, faktör yükleri ve toplam varyansı açılayabilme oranlarına göre sırasıyla "Çalgı Tekniği", "Ön Hazırlık ve Isınma", "Postür ve Teknik", "Yorumlama ve Cümleleme", "Ritmik Çalışma ve Parmaklandırma", "Performans Sonrası Etkinlik" ve "Deşifre Tekniği" alt ölçeklerinden oluşmaktadır. Çalgi Tekniği alt ölçeğinde 7, Ön Hazırlık ve Isınma alt ölçeğinde 7, Postür ve Teknik alt ölçeğinde 5, Yorumlama ve Cümleleme alt ölçeğinde 4, Ritmik Çalışma ve Parmaklandırma alt ölçeğinde 3, Performans Sonrası Etkinlik alt ölçeğinde 3 ve Deşifre Tekniği alt ölçeğinde 3 madde yer almaktadır. Açıklayıcı faktör analizi sonuçlarına göre elde edilen 7 faktörün açıklanan toplam varyansa katkısı \%65.448 oranında saptanmıştır. Her bir faktörün Cronbach Alpha güvenirlik katsayıları incelendiğinde, katsayıların 0.662 ile 0.883 arasında değiştiği görülmektedir. Tüm alt ölçeklerin birbirleriyle ve toplam puanlar olan ilişkileri 0.001 anlamlılık düzeyindedir. 


\section{EXTENDED ABSTRACT}

\section{Development of Piano Study Habits Scale \\ * \\ Hakan Bağcı - Alkın Toy \\ Kocaeli University}

Habits are behaviors that are done occasionally at first, and then behaviors that become routines and finally the indispensable actions, thoughts or emotions of daily life (Orhan, 2017, p.303). A habit is a learned behavioral pattern which is regularly repeated. Habits pave the way for actions that are automatically done (Gobet, Chassy ve Bilalic, 2011, p.347).

Habits even go beyond the learned or automatic behavioral patterns of an individual. Greetings, rituals or other social traditions and behaviors make societies form habits. An individual goes in for certain habits while learning to read a language and during his linguistic development, an individual also forms habits of idiomatic language, written language and comprehension (Graves, 2017, p.283).

As they result in actions, habits helps us to predict the behaviors. Habits are also signs of future behaviors of an individual. (Hogg ve Vaughan, 2010, p.105). Therefore, for success and achievement, habits play an important role.

There are various attitudes and behaviors that shape the students' piano playing habits. These behaviours include warm-up exercises before playing the instrument, exercises and etude studies, correct hold or position of the instrument, analysis of the musical work, deciphering the musical work, memorising and so on. The behaviors listed above are among the one which are common for all the instruments in various musical behavior studies (Küçükosmanoğlu ve diğ. 2016, p.189).

It was confirmed that the use of learning strategies in piano training is more effective and boosting in increasing students' success and in raising students' metacognitive awareness when compared to the classical piano training methods (Ertem, 2014, p.20).

The most common and current classification of widely used learning strategies was done by Weinstein AND Mayer in 1986 (Ertem, 2014, p.20-21): 1Rehearsal strategies, 2- Elaboration strategies, 3- Organization strategies, 4Metacognition strategies, 5- Motivation strategies. 
During university education, essential knowledge and functional skills should be taught to every single student in piano training (Jelen, 2013, p.260). In today's world, as well as possessing certain measurement techniques to decide performance success for various instruments (Abeles, 1973; Barnes, 2002; Ekhohn, 1997), we also have scales to evaluate performance for the piano (Grançer, 2009).

However, for a clear and better guidance of the students and to test the effects of this guidance on students' success, there is a dire need of a scale to measure piano playing habits for teachers and researchers.

\section{Problem}

The main objective of this study is to develop a valid and reliable scale to evaluate students' piano playing habits in piano courses which are among compulsory courses in music departments of many universities.

\section{Methodology}

In this part, the technical information related to the sample, scale and data analysis procedures was given in detail below.

\section{Population and Sample}

The population of this study consisted of students from different departments of music education from different universities. Moreover, the sample consisted of 108 randomly selected students (104 female and 84 male students) studying at music departments of fine arts faculties of four different state universities during the academic year of 2017-2018.

\section{Scale Development}

In order to develop a scale, the first thing to be done was a thorough literature review with the aim of deciding the items related to the habits of instrument players and eventually a total of 52 items were collected in a pool. The items that were suitable for the scale and represented the behaviors that were meant to be evaluated are determined according to expert opinions (Karasar, 1999, 
p.151). The content validity of the scale is insured via expert opinions. In this study, the number of the items in the scale was set to 32 after considering expert opinions. The scale was designed as a 5 point likert type scale scoring from one to five.

\section{Data Collection}

The scale developed in this study was given to the students from four different universities, who were in the sample group, and the students were motivated to answer the questions in the scale frankly and sincerely.

\section{Data Analysis}

The validity and reliability studies of the scale were carried out with the help of the answers from students in the sample group. An exploratory factor analysis was done in order to present the structure of the scale. In order to reveal the construct validity of the Piano Studying Habits Scale, another exploratory factor analysis was carried out by using Quartimax rotation method and principal component analysis. As a result of the factor analysis, factor loads of the items in the scale were determined to be over 0.30 (Büyüköztürk, 2015; Eroğlu, 2008; akt: Evci ve Aylar, 2017, p.50). Therefore, the minimum factor load was set to be 0.30 in the analysis. For the sub dimensions of the scale and the overall reliability, Cronbach's Alpha coefficient was calculated.

\section{Result}

In this study, in order to evaluate the Piano Studying Habits, a scale consisting of 32 items was developed. Cronbach's Alpha coefficient of the scale was found to be 0.940 . The scale is a five point likert type scale, scoring between 1 to 5 .

The seven sub-dimensions of the scale can be listed according to their factor loads and total variance as follows: "Instrument Technique", "Preparation and Warm-up", "Posture and Technique", "Interpretation and Phrasing", "Rhythmic Work and Fingering", "Post-performance Activity" and "Deciphering Technique". There are 7 items in Instrument Technique, 7 items in Warm-up, 5 items in Posture and Technique, 4 items in Interpretation and 
Phrasing, 3 items in Rhythmic Work and Fingering, 3 items in Post-performance and 3 items in Deciphering Technique categories. The contribution of the sevent factors acquired through the exploratory factor analysis to the total variance was found to be \%65.448. When Cronbach's Alpa coefficients of each factor was analyzed, the coefficients were observed to be ranging between 0.662 and 0.883 . The relationships of the sub-scale with each other and the total scores is at 0.001 significance level.

\section{Kaynakça / References}

Abeles, H. (1973). Development and validation of a clarinet performance adjudication scale. Journal of Research in Music Education. 21, 246-255.

Akgül A. (2005). Tibbi araştırmalarda istatistiksel analiz teknikleri SPSS uygulamaları. (3. Bask1), Ankara: Emek Ofset Ltd.Şti.

Barnes, G. (2002). Development and validation of a string performance rating scale. Journal of Research in Music Education, 50 (3), 245-255.

Büyüköztürk, Ş. (2015). Sosyal bilimler için veri analizi el kitabı. (21. Baskı). Ankara: Pegem Yayınları

Ekhohn, E. (1997). Evaluation of solo vocal performance: A comparison of students with experts. Applications of Research in Music Education, 16 (1), 3-7.

Eroğlu, A. (2008). Faktör analizi. (Ş. Kalaycı Ed.), SPSS uygulamalı çok değişkenli istatistik teknikleri, Ankara: Asil Yayınları.

Ertem, Ş. (2014). Piyano eğitiminde öğrenme süreci ve öğrenme stratejileri kullanmanın yeri ve önemi. Sanat Eğitimi Dergisi (SED), 2 (2), 1-26, DOI:10.7816/sed-02-02-01

Evci, N. ve Aylar, F. (2017). Öğretmenlerde tükenmişlik düzeyleri öz-alg1 ölçeğinin geliştirilmesi: Geçerlik ve güvenirlik çalışması. Gazi Ĕ̆itim Bilimleri Dergisi (GEBD), 3 (1), 44-58. ISSN: 2149-4932

Gobet, F., Chassy, P. ve Bilalic, M. (2011). Foundations of cognitive psychology. New York: McGraw \& Hill. ISBN: 978-00-7711908-9

Grançer, N. (2010). Piyano performansının değerlendirilmesi. Yayınlanmamış Doktora Tezi. Marmara Üniversitesi Eğitim Bilimleri Enstitüsü, İstanbul

Graves, M. (2017). Habits, tendencies, and habitus: the embodied soul's dispositions of mind, body, and person. Habits in Mind. (Eds. Gregory R. Peterson, James A. Van Slyke, Michael L. Spezio, Kevin S. Reimer). Leiden: Koninklijke Brill NV. ISBN: 978-90-04-34294-1

Hogg, M.A ve Vaughan, G.M. (2010). Essentials of social psychology. London: Pearson Education Limited. ISBN 978-0-13-206932-8 
Jelen, B. (2013). Türkiye' de müzik öğretmeni yetiştirme sürecinde piyano eğitiminde karşılaşılan sorunlar. Rast Müzikoloji Dergisi, 1 (1), 258-285.

Karasar, N. (1999). Bilimsel araştırma yöntemi. (9. Basım). Ankara: Nobel Yayın Dağıtım Ltd. Şti.

Küçükosmanoğlu, H. O., Babacan, E., Babacan M. D. ve Yüksel, G. (2016). Müzik eğitiminde çalgı çalışma yöntemleri ölçek geliştirme çalışması. İnönü Üniversitesi Sanat ve Tasarım Dergisi, 6 (13), 189-198, ISSN: 13099876, E-ISSN: 1309-9884

Metin, Y. (2014). İstatistiğe yönelik tutum ölçeği: Geçerlilik ve güvenirlik ça1ı̧̧ması. Pamukkale Üniversitesi Eğitim Fakültesi Dergisi, 36 (II), 59-75.

Orhan, R. (2017). Alışkanlık. Kırıkale Üniversitesi Sosyal Bilimler Dergisi, 7 (2), 301306.

Özdamar, K. (1999). Paket programlar ile istatistiksel veri analizi 1. Eskişehir: Kaan Kitabevi

Sarı, A. (2016). Psikiyatri kliniğinde yatan hastalar için hemşire gözlem ölçeği geliştirilmesi geçerlik ve güvenirlik çalışması. Yayımlanmamış Yüksek Lisans Tezi. Dokuz Eylül Üniversitesi Sağlık Bilimleri Enstitüsü, İzmir

Weinstein, C. E. ve Mayer, R. E. (1986). The teaching of learning strategies. handbook of research on teaching. New York: American Educational research Association, Mc Millan

\section{Kaynakça Bilgisi / Citation Information}

Bağcı, H. ve Toy, A. (2020). Piyano çalışma alışkanlıkları ölçeği geliştirme çalışması. OPUS-Uluslararası Toplum Araştırmaları Dergisi, 15(21), 583-603. DOI: $10.26466 /$ opus.621102 